ture conditions, the charge to be pushed when the centre of the coke reaches $700^{\circ} \mathrm{C}$., seem likely to produce a more combustible coke. This opinion is based on some theory, on a fair amount of careful laboratory experiments, with but little large-scale confirmation, however.

Of scientific contributions there were naturally few; naturally, because of the newness, vastness and difficult character of the field. Concerning carbonisation, profound ignorance prevails. As to treatment and events beyond the hydraulic main there is still room for discussion-witness the recent contribution to this by Dr. Smith and Mr. Finlayson-but in respect to treatment and events, from the cold coal to the hydraulic main, there is no useful discussion. We do not know. There is much methane in coal gas; the methane has presumably been at $1000^{\circ} \mathrm{C}$. or so. At this temperature methane deposits carbon and produces hydrogen. The shiny carbon-termed methane carbon-is accompanied by at least two, if not more than two, physically different forms of carbon. Moreover, from the deposit, it is almost as easy to pick out pieces of naphthalene as it is pieces of carbon.

At the Conference the terms reactivity and combustibility were used as synonyms. Korrevar has shown that they are as synonymous as silica and glass. Mr. E. V. Evans brought forward a new method for the determination of the combustibility of coke, as regards the utility in the open grate, and the method promises much. But as to reactivity, that intrinsic property of carbon, not much was said. The reactivity of carbon, which lies at the basis of the combustibility of that impure substance, coke, depends on the physical condition of the carbon, and at once we are back to the carbon deposits from methane cracking. If we know nothing concerning these deposits carbon, what are we to say of our real knowledge of coke?

As Dr. H. M. Travers pointed out, at almost every stage of the carbonisation some very pertinent and unanswerable questions may be put. Why is primary tar formed at all-what is the mechanism of it? Why does coke at the later stages of carbonisation evolve hydrogen for the most part, and that in bursts with rise of temperature? He also put in a plea for research into fundamentals of fuel utilisation ; if this be undertaken, then the Conference may well be a momentous one. $\mathrm{He}$ considers that the universities should undertake the work rather than, for example, the Fuel Research Board. His opinion is that progress is not likely to follow the permutations and combinations of well-known works processes. A difficulty is created, however, by the financial position of most of the universities of Great Britain. Many public-spirited industrialists know this, and there may be those, whether individuals or corporations, who would care to contribute towards the cost of research into fundamentals of this character.

Should means become available for the prosecution of the fundamental researches indicated, then a plea might be entered for the University of Sheffield, where there is a well-established school of fuel research. The list, distributed at the meeting, of work in progress, served to indicate the varied and extensive character of its activities. One could pass from Fuel Research Board apparatus, solvent resolution, to spontaneous combustion, momentary heating of coal, desulphurisation, combustion, coal constitution, synthetic ulmins, hydrogenation, flame work and microscopic work.

The Conference adjourned until February for a meeting at Manchester.

S. L. B. Etherton.

\title{
The Early Nilotic, Libyan, and Egyptian Relations with Minoan Crete.
}

THE Huxley Memorial Lecture of the Royal Anthropological Institute for I925 was delivered by Sir Arthur J. Evans at the rooms of the Royal Society on Tuesday, November 24. The chair was taken by Prof. C. G. Seligman, president of the Institute.

Sir Arthur Evans said Crete might be described as a half-way house between three continents, Europe, Asia, and Africa. Its fortunate situation marked it as the point where the primitive culture of our continent was first affected by the older civilisations of Egypt and the East. The most ancient geographical relations of Crete lay with Anatolia and the East. Man entered 'Crete from the Anatolian side; he may even have found the dwarf hippopotamus surviving from the times of the land-bridge of Miocene and Pleistocene times; but Palæolithic discoveries in Crete are still wanting and human remains from Neolithic times are still to seek. From Middle Minoan times a brachycephalic element is perceptible, mixed with the older dolichocephalic inhabitants, which may be due to an intrusion of "Armenoids" from Asia Minor, for which a portrait on a Middle Minoan seal supplies an argument. Archæological, religious, and linguistic evidence all point to a root connexion between Crete and Anatolia. The primitive female steatopygous figures from the Neolithic strata of Knossos find remarkable parallels from Asia Minor and so far afield as the Euphrates and Caspian. Stone maces and monochrome pottery show similar affinities. The pre-Hellenic language is related to old Carian and its kindred tongues.

It has been supposed that Egyptian relics found in connexion with Minoan and Mycenæan Crete arrived by the Syrian or Anatolian route, but this is unsupported by any evidence as regards the earlier contact of Crete with the Nile Valley. There is abundant proof that early man was not averse from deep-sea voyages. It is natural to suppose that in the East Mediterranean navigation began in the Egean island world. Neither the Syrian nor the Libyan coast was favourable to its rise. Of Cretan vessels, the earliest representation is a clay model from Palaikastro of the First Early Minoan Period, which may be compared with the Nile craft such as those shown on the pottery of Naqada. There was a general use of sailing craft from an early date, and vessels with a single mast are of constant recurrence at the beginning of the Second Early Minoan Period in the first half of the third millennium B.C.

Evidence accumulating since 1890 of early relations between Crete and Egypt going back to the fourth Dynasty received remarkable confirmation from the beginning of the excavations at Knossos, in the form of imported Egyptian stone vessels of late prehistoric and protodynastic age and, more important, in derivative native Cretan forms in softer stone such as steatite and serpentine. In a Neolithic house of rectangular form found under the Central Court of the original Palace of Knossos, with fixed hearth of Anatolian type, was found among objects of pure Stone Age tradition a copper axe which must be regarded as an importation, not improbably from the Nile Valley. Two finds of special importance from this site were a gallipot-like vessel with clear traces of tubular drilling closely resembling a type of late predynastic and protodynastic Egyptian vessels, and two fragments of vessels of variegated stone which, 
although like nothing found in Egypt or elsewhere, appear to be exotic and show that the Nilotic usage of stone vessels wrought in decorative materials had taken root at Knossos in the late Neolithic phase.

Among other elements of Cretan culture showing affinities to the early culture of the Nile and of the indigenous inhabitants of the opposite Libyan coasts, are the large stone ossuaries in the beehive form of the Messara plain on the southern border of the island, contrasting with the rectangular habitations of Crete. Stone idols from Hagia Triada curiously recall those found in predynastic Egypt. They show the high head and pointed beard of the Nilotic race, and possibly passed to Crete from Libya. The Cretan mode of head-dress and the type of loin clothing show either a resemblance or a general analogy with that of the Libyans. The Libyan Delta goddess appears to have been, in part at least, incorporated in the Cretan mother goddess, as is shown in the form of bow, arrows, and shield which are the attributes of the former. In the stone ossuaries, the discovery of palettes of stone similar to those used by the predynastic Egyptians for antimony and malachite to adorn the person are peculiarly significant.

These striking correspondences in forms and usage, and especially in the contracted burials of the vaulted tombs of Messara, the dolichocephalic skulls, and the recurrence of foot-shaped amulets of stone, suggest a settlement of a proto-Libyan element in the southern foreland of Crete. These tombs are of a true beehive type, but they differ from the Mycenæan examples in their entrance system. They represent a sepulchral type which has a wide diffusion in the old Libyan region of North Africa. This proto-Libyan settlement became entirely assimilated in the Old Cretan population, but the engrafting of this artistic element on the indigenous island stock may well have contributed to the later bloom of Minoan culture.

At the conclusion of the lecture, the president of the Institute presented the Huxley Medal to Sir Arthur Evans.

\section{The Flame Spectra of Carbon Monoxide and Water Gas.}

TWO papers by Mr. F. R. Weston, recently published in the Proceedings of the Royal Society (A, vol. I09, I925, pp. I76-I86 and 523-526), embody the results of researches into the flame spectra of carbon monoxide, hydrogen, water gas, etc., which he has conducted at the Imperial College of Science and Technology under the joint supervision of Profs. W. A. Bone and A. Fowler. The object of the researches was to elucidate certain aspects of the combustion of carbon monoxide, and notably whether or not this gas interacts directly with oxygen in flames, a point which has been much disputed amongst chemists during the past forty years, but now seems to be in the way of being definitely cleared up by the spectroscope.

The spectrum of a flame of undiluted carbon monoxide burning in air (or oxygen) at atmospheric pressure is shown to consist of a banded radiation, extending from 5000 A.U. in the visible region to $2200 \AA$.U. far in the ultra-violet, upon which a continuous spectrum is superimposed. Both the banded and continuous parts of the spectrum, which are associated with the characteristic colour and actinic properties of a carbon monoxide flame, are most probably due to divect interactions between carbon monoxide and oxygen molecules in the flame, without any intervention of steam. At the same time, unless both the carbon monoxide and oxygen are previously dried before combustion, the spectrum shows some characteristic "steam lines," due to interactions between $\mathrm{CO}$ and $\mathrm{OH}_{2}$ molecules in the flame, which proceed simultaneousily with, and independently of, the $\mathrm{CO}$ and $\mathrm{O}_{2}$ interactions.

As the carbon monoxide in the burning gas was progressively replaced by hydrogen, both the banded and continuous parts of the spectrum rapidly faded away, until with an equimolecular (that is, $50 \mathrm{CO}+5 \mathrm{O} \mathrm{H}_{2}$ by volume) mixture of the two combustible gases (water gas) only "steam lines" remained visible in the spectrum, the characteristic CO-radiation and flame-colour having almost entirely disappeared.

When a flame of undiluted carbon dioxide was burnt (undried) in oxygen under reduced pressure, the banded part of the spectrum became more distinct and the continuous part less intense as the pressure was diminished; the "steam lines" were invariably present in the spectrograms. When a flame of carbon monoxide, previously dried by passage through strong sulphuric acid, was burnt at atmospheric pressure in oxygen, similarly dried, the "steam lines" in the resulting spectra had almost disappeared (they were only faintly visible), whereas the intensity of the continuous part of the spectrum remained undiminished.

The conclusion drawn from the experiments is that in the flame of pure (undried) carbon monoxide two sets of independent interactions occur simultaneously, namely: (a) direct interactions between carbon monoxide and oxygen, exciting radiations which give rise to the continuous and banded parts of the spectrum, and to the characteristic blue colour of the flame, and $(b)$ interactions between $\mathrm{CO}$ and $\mathrm{OH}_{2}$ molecules, which originate the "steam lines" in the spectrum. When hydrogen is gradually added to the burning gas the relative proportions of the firstnamed interactions diminish rather rapidly and proportionately more of the carbon monoxide is burnt by interaction with $\mathrm{OH}_{2}$-molecules, until when an equimolecular mixture of carbon monoxide and hydrogen is reached, the carbon monoxide-steam interactions occur to the practical exclusion of the carbon monoxide-oxygen interactions. These experiments have afforded the first clear evidence that in an ordinary carbon monoxide flame both sets of interactions are going on independently and simultaneously.

\section{School Natural History Societies.}

THE Marlborough College Natural History Society is interesting as a school institution which has had an unbroken existence since I864, when it was founded under the auspices of the then headmaster, later Dean Bradley of Westminster; it now issues its seventy-third printed report. Marlborough is situated in an unique position for this study, with some primeval forest in Savernake on one side and the open savannahs of the Downs on the other. Between the two runs the Kennett, here quite a small sluggish stream noted for its excellent trout-fishing, with beds of willows and water meadows by its sides. Near its head waters, from six to seven miles away, lie Silbury Hill and Avebury, the latter with its immense stone circles. The Downs show dolmens and tumuli, most of the latter probably of much later age, and there 